\title{
Images of internal tides near the Norwegian continental slope
}

\author{
W. Steven Holbrook, ${ }^{1}$ Ilker Fer, ${ }^{2}$ and Raymond W. Schmitt ${ }^{3}$ \\ Received 27 April 2009; revised 14 October 2009; accepted 20 October 2009; published 31 December 2009.
}

[1] Internal tides, or internal gravity waves propagating at tidal frequencies, play an important role in ocean mixing but are challenging to detect and map over large spatial sections in the ocean's interior. We present seismic images of oceanic finestructure in the Norwegian Sea that demonstrate that semidiurnal $\left(\mathrm{M}_{2}\right)$ internal tidal beams can be seismically imaged. We observe bands of seismic reflections that cross isotherms and closely mimic the expected internal tide ray characteristic over hundreds of meters vertically and tens of $\mathrm{km}$ laterally, in an area where critical seafloor slopes are common. Coincident temperature and density profiles show that the reflections come from reversible finestructure caused by internal wave strains. Where the beams intersect the seafloor, indications of enhanced mixing are present, including finestructure disruption and enhanced internal wave energy. These results suggest that seismic oceanography can be an effective tool in studies of ocean mixing by internal tides. Citation: Holbrook, W. S., I. Fer, and R. W. Schmitt (2009), Images of internal tides near the Norwegian continental slope, Geophys. Res. Lett., 36, L00D10, doi:10.1029/2009GL038909.

\section{Introduction}

[2] Internal tides are internal gravity waves propagating at tidal frequencies, often at the semidiurnal $\left(\mathrm{M}_{2}\right)$ frequency. Internal tides are thought to form by conversion of barotropic tides to baroclinic energy over variable topography [Garrett and Kunze, 2007], especially near critically inclined continental slopes [Baines, 1982; Cacchione et al., 2002]. While low-mode internal tides can propagate for thousands of kilometers [e.g., Alford and Zhao, 2007], highmode (short-vertical-wavelength) internal tides can dissipate near their source regions [Moum et al., 2002] and may thus contribute to ocean mixing [Egbert and Ray, 2000]. Although internal tidal beams have been detected in a few cases [Pingree and New, 1989; Lueck and Mudge, 1997; Lien and Gregg, 2001; Rudnick et al., 2003; Nash et al., 2004; Martin and Rudnick, 2007; Cole et al., 2009], they are challenging to measure, as they require in-situ measurements over a substantial horizontal and vertical region in the area of interest. Here we present new observations showing an interpreted internal tidal beam in unprecedented lateral and vertical detail, using seismic reflection data.

[3] Seismic oceanography, a relatively new technique for imaging thermohaline finestructure within the ocean

\footnotetext{
${ }^{1}$ Department of Geology and Geophysics, University of Wyoming, Laramie, Wyoming, USA.

${ }^{2}$ Geophysical Institute, University of Bergen, Bergen, Norway.

${ }^{3}$ Department of Physical Oceanography, Woods Hole Oceanographic Institution, Woods Hole, Massachusetts, USA.
}

Copyright 2009 by the American Geophysical Union. 0094-8276/09/2009GL038909\$05.00
[Holbrook et al., 2003], exploits low-frequency (10$150 \mathrm{~Hz})$ reflections from impedance contrasts in the water column to produce cross-sectional images of thermohaline finestructure. The impedance contrasts are caused primarily by vertical temperature gradients [Holbrook et al., 2003; Nandi et al., 2004] that create reflection coefficients (R) much weaker $\left(\mathrm{R} \sim 10^{-3}-10^{-4}\right)$ than those recorded from the solid earth $\left(\mathrm{R} \sim 10^{-1}\right)$. The technique has been shown effective at imaging a wide variety of oceanic processes, including oceanic fronts [Holbrook et al., 2003; Tsuji et al., 2005; Nakamura et al., 2006], eddies [Biescas et al., 2008; Ruddick et al., 2009], water-mass boundaries [Nandi et al., 2004], and internal wave displacements [Holbrook and Fer, 2005; Krahmann et al., 2008]. In this paper we show that seismic reflection imaging can also detect high-mode internal wave beams.

\section{Data Acquisition}

[4] Seismic data were acquired in September 2003 in the Norwegian Sea (Figure 1) aboard the R/V Maurice Ewing, using a 6-gun, $221(1340 \mathrm{cu}$. in.) airgun array fired every $37.5 \mathrm{~m}$ and a 6-km-long, 480-channel hydrophone array. This produced data with a frequency range of $10-120 \mathrm{~Hz}$ and a dominant frequency of about $50 \mathrm{~Hz}$ (dominant wavelength of $\sim 30 \mathrm{~m}$ ). The ship's speed was constant at about $2.5 \mathrm{~m} / \mathrm{s}$, so that it took about 2.2 hours to acquire data across a $20-\mathrm{km}$-long transect. In-situ hydrographic information was provided by temperature and salinity data on XBT and XCTD profiles acquired during seismic acquisition [Nandi et al., 2004]. Expendable instruments were deployed from the gun boom of the Ewing during seismic acquisition, so that the temperature and salinity data are coincident with the seismic images in space and time.

[5] Examples of data on two seismic lines acquired perpendicular to the continental margin are shown in Figures 2 and 3 . Both lines show a predominance of reflectance in the mid-water column at depths of $\sim 400$ $600 \mathrm{~m}$; these reflections correspond to a water-mass boundary between the Atlantic Water (AW) carried by the Norwegian Atlantic Current and underlying Norwegian Sea Deep Water (NSDW) [Nandi et al., 2004] (Figure 2). Most reflections in these sections follow isotherms, but in both sections reflections are visible that are inclined several degrees from the horizontal and climb several hundred meters through the water column; on Line 11 (Figure 2) these can be seen to cross isotherms. In the next section we show that these patterns can be explained as reflections from high-mode internal tides.

\section{Imaging $\mathrm{M}_{2}$ Beams}

[6] Internal wave beams propagate along a group velocity vector (or ray characteristic) determined by the relative 


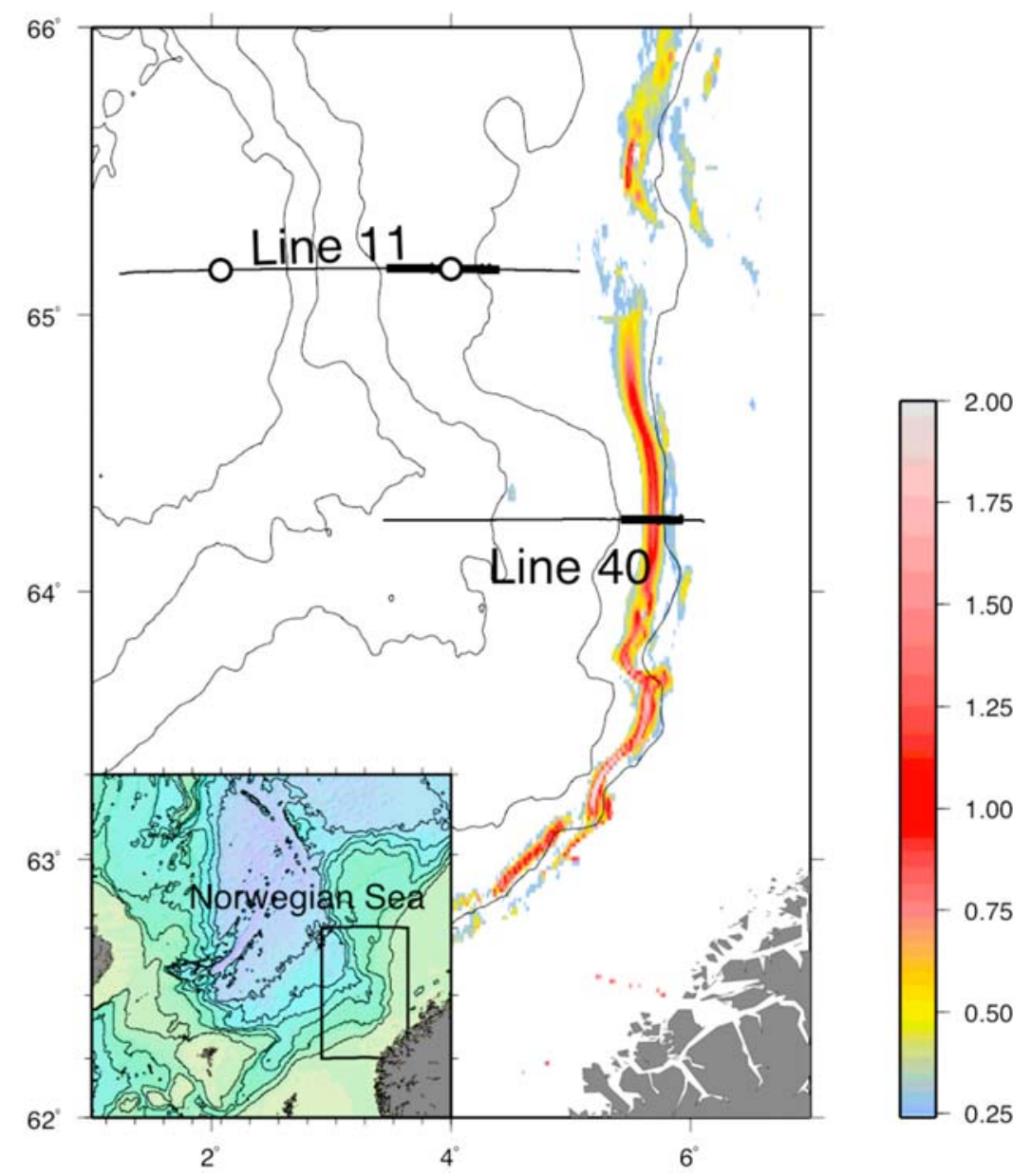

Figure 1. Location figure of Norwegian Sea, showing seismic lines (thin lines) and positions of expendable bathythermograph (XBT) and conductivity-temperature-depth (XCTD) probes (open circles). Bold lines show portions of seismic lines shown in Figures 2 and 3. Color scale shows ratio $\gamma / \mathrm{c}$ of the slope of the seafloor $(\gamma)$ to the slope of semidiurnal $\left(\mathrm{M}_{2}\right)$ internal tide (c).

magnitudes of three frequencies: the internal wave frequency $\omega$, the local buoyancy frequency $\mathrm{N}(\mathrm{z})=[-(\mathrm{g} / \rho) \partial \rho / \partial \mathrm{z}]^{1 / 2}$, and the local inertial (or Coriolis) frequency, $f=1.31 \times$ $10^{-4} \mathrm{~s}^{-1}$ at $64^{\circ} \mathrm{N}$. Here, $g$ is the acceleration of gravity and $\rho$ is the average potential density. The inclination of the group velocity vector of the incident internal waves follows the characteristic

$$
c=\tan \theta= \pm\left(\frac{\omega^{2}-\mathrm{f}^{2}}{N^{2}-\omega^{2}}\right)^{1 / 2}
$$

where $\theta$ is the angle relative to the horizontal. Given $N(z)$, we can predict the propagation angle $(\theta)$ of $\mathrm{M}_{2}$ internal waves, which have a frequency $\omega$ of $1.41 \times 10^{-4} \mathrm{~s}^{-1}$. We calculated $\gamma / \mathrm{c}$ in our study area [Cacchione et al., 2002], using equation (1) to calculate $c$ for $\mathrm{M}_{2}$ internal waves and 1-minute resolution bathymetry [General Bathymetric Chart of the Oceans, 2004] to determine the slope of the sea bed, $\gamma$ (Figure 1).

[7] Internal gravity waves are transverse waves, with a phase velocity at right angles to the group velocity inclined at the slope $c$. Similar relations are seen in tank experiments of internal waves [Dauxois et al., 2004], where internal wave beams produce "strains" with alternating bands of compression and dilatation aligned parallel to the group velocity vector; these are easily imaged in Schlieren images to show the familiar "St. Andrew's cross" [e.g., Thorpe, 2005, p. 57]. Here we define "strain" following Thorpe [2005] as the vertical distance between two given isopycnal surfaces divided by their mean separation, and not in the formal sense of the strain tensor in an incompressible fluid. In this sense, a propagating internal wave causes zones of intensified or weakened "strain," which are aligned with the group velocity vector of the wave [Thorpe, 2005, p. 60]. These strains will produce reversible finestructure capable of causing acoustic reflections if the wave strains occur at sufficiently short vertical wavelengths; the inclination of the reflections would then mark the group velocity vector. Nandi et al. [2004] showed that internal wave strains with a dominant vertical wavelength of $\sim 5-10 \mathrm{~m}$ are responsible for acoustic reflections near an XCTD on Line 11 in the Norwegian Sea. Here we show that these same reflections follow an $\mathrm{M}_{2}$ internal tide characteristic.

[8] The buoyancy frequency profile, $\mathrm{N}(\mathrm{z})$, for Line 11, calculated from the local density profile determined from the coincident XCTD, peaks in the thermocline, where 


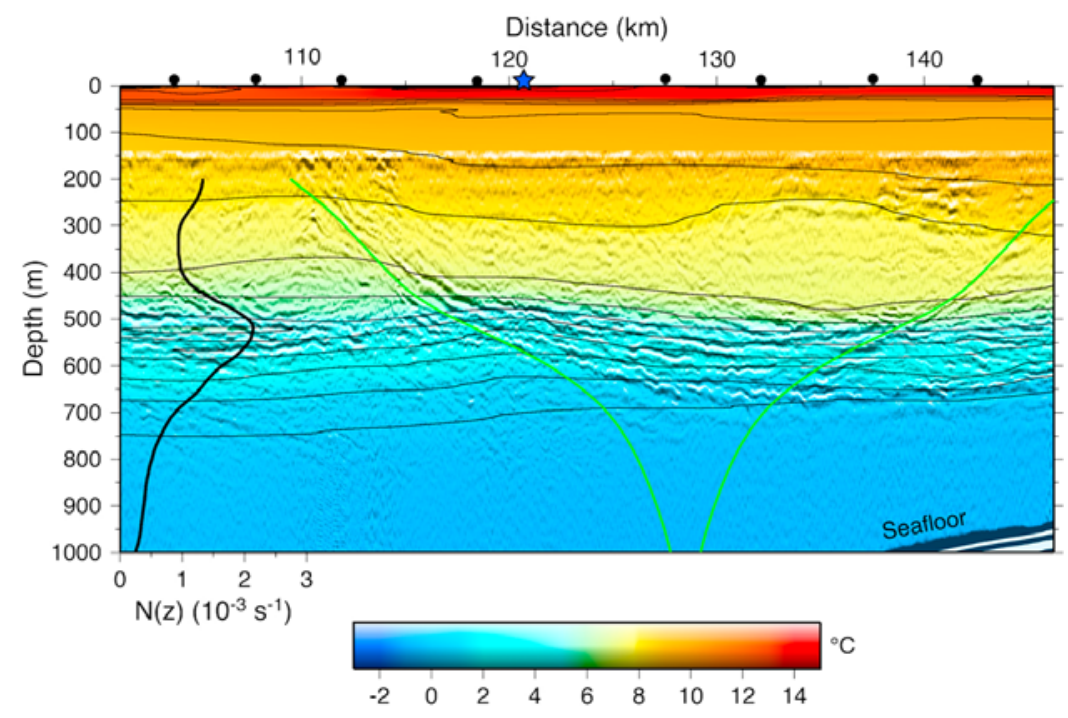

Figure 2. Portion of stacked seismic data on Line 11, superimposed on temperature structure (color scale) measured by XBTs deployed at $\sim 5 \mathrm{~km}$ spacing. Solid circles show locations of XBTs; blue star shows location of XCTD (see Nandi et al. [2004] for more detail). Thin black lines show temperature contoured at $1{ }^{\circ} \mathrm{C}$ intervals. Strong reflections correspond to finestructure in the thermocline that marks the boundary between AW and underlying NSDW [Nandi et al., 2004]. Bold line shows mean buoyancy frequency $(\mathrm{N})$ structure determined by XBTs and XCTDs deployed during seismic survey. Green lines show predicted trajectory of $\mathrm{M}_{2}$ internal waves, derived from mean $\mathrm{N}(\mathrm{z})$ structure. Predicted $\mathrm{M}_{2}$ trajectories show a good match to observed shapes of reflections that cross isotherms, e.g., the concave-upward reflections just above the thermocline. Seafloor reflection is visible at lower right.

temperature and density change rapidly between the AW and NSDW (solid line, Figure 2). This N(z) profile dictates that internal waves have a concave-upward shape above the thermocline, be closer to horizontal in the thermocline, and be concave-downward beneath the thermocline (green line, Figure 2). This distinctive pattern is visible in numerous locations on our seismic profiles, most notably on Line 11, where weak, sloping reflections that cross isotherms and curve into the thermocline are observed (Figure 2). The close match between the observed reflections and the predicted $\mathrm{M}_{2}$ trajectory provides strong evidence that the reflections are internal tide beams.

[9] Similarly inclined reflections are present in other lines in our survey as well, including Line 40 (Figure 3), which lies about $100 \mathrm{~km}$ south of Line 11 . On Line 40, numerous concave-upward reflections are observed adjacent to the continental slope, some of which have amplitudes as strong as those observed in the thermocline. As on Line 11, these reflections closely mimic the predicted trajectory of an $\mathrm{M}_{2}$ internal tide, deviating at most $75 \mathrm{~m}$ vertically from the predicted path over horizontal distances of $>10 \mathrm{~km}$. (An exact match on this line is not to be expected, since the $\mathrm{N}(\mathrm{z})$ profile comes from XCTD data located elsewhere in the region; moreover, a single $\mathrm{N}(\mathrm{z})$ profile will not capture lateral variability in the buoyancy frequency, nor account for advection by currents, both of which will affect internal wave trajectories.) We interpret these reflections to represent high-mode internal tide beams, which are likely produced by conversion of low-mode internal tides to higher modes upon reflection from the near-critical slope. Strong internal tides are to be expected here, since near-critical slopes are common in this area (Figure 1). Indeed, the seafloor on Line 40 shows a planar shape at least $15 \mathrm{~km}$ long in the downslope direction, which happens to be inclined very near the critical angle (Figure 3).

\section{Discussion and Conclusions}

[10] Several lines of evidence indicate that internal tides have been imaged in our seismic data. First, the reflections in question cross isotherms over many degrees $\mathrm{C}$, which suggests an internal-wave origin. Second, where those reflections are intersected by XCTD profiles, the temperature and density gradients change in lockstep over vertical distances of 5-10 m [Nandi et al., 2004], which would be expected for vertical wave strains caused by high-mode internal waves. Third, critical or near-critical slopes are present on the continental slope in the vicinity of our seismic lines. Finally, the trajectories of the reflections in

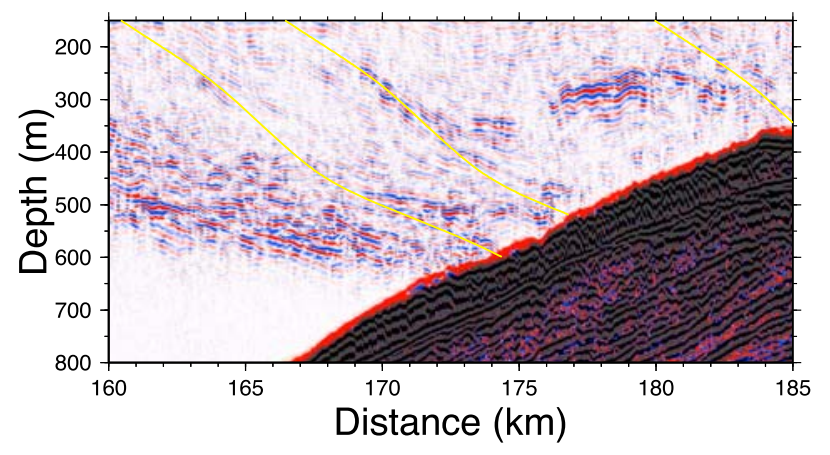

Figure 3. Stacked seismic section on Line 40. Clear $\mathrm{M}_{2}$ internal waves radiate from the slope (yellow lines), upslope of which severely disrupted finestructure is observed, possibly representing a zone of turbulence. 
question closely follow the predicted $\mathrm{M}_{2}$ internal tide characteristic, including a distinctive upward-concave shape above the mid-water thermocline. Other possible sources of isopycnal-crossing reflectors seem unlikely here: in particular, while isopycnal-crossing reflections have been reported around large eddies [e.g., Bullock, 2006], our section lacks evidence for strong eddies. Similarly, the "McIntyre instability", which can produce isopycnal-crossing structures as a result of the unequal mixing of mass and angular momentum in the laboratory [e.g., Ruddick, 1992], also would require an eddy or other source of rotation, which is lacking here. We believe that internal wave beams are the most likely source for the isopycnal-crossing reflectivity imaged in Figures 2 and 3.

[11] Examination of seismic images in our area shows that the $\mathrm{M}_{2}$ internal tides commonly originate on the continental slope where the seafloor is inclined at the critical angle to $\mathrm{M}_{2}$. When the slope of the seabed $(\gamma)$ matches the characteristic slope (c) of an internal wave, critical reflection occurs. Observations supported by numerical work [Nash et al., 2004] show that low-mode $\mathrm{M}_{2}$ baroclinic tides impinging on a near-critical continental slope create beams of higher-mode $\mathrm{M}_{2}$ reflected energy that radiate offshore. Our observed $\mathrm{M}_{2}$ internal tides must be high-mode: in order to produce finestructure sharp enough to be imaged at seismic wavelengths, internal wave strains must have short vertical wavelengths. Indeed, the 5-10 m vertical wavelengths of vertical wave strain measured by Nandi et al. [2004, Figure $4 \mathrm{~A}$ ] on Line 11 would correspond to waves of mode $>100$ in water depths of $1000 \mathrm{~m}$. Theory [Thorpe, 1987], observations [Eriksen, 1985], numerical models [Legg and Adcroft, 2003; Nash et al., 2004] and laboratory experiments [Ivey and Nokes, 1989] show that critically reflecting internal waves enhance shear at the bottom, leading to shear instability and dissipation. Over much of our study area, the continental slope is inclined at or near the critical angle for $\mathrm{M}_{2}$ internal waves at water depths of 400-700 m (Figure 1), so critical reflection and turbulence can be expected.

[12] Accordingly, the appearance of thermocline finestructure in our seismic images changes dramatically near the continental slope in ways that suggest wave steepening, wave breaking, and turbulence. The observations include disrupted finestructure near the slope and increased wavenumber (shorter wavelength) and waveheight as the slope is approached [Holbrook and Fer, 2005]. On Line 40, upslope of the region of $\mathrm{M}_{2}$ wave radiation, finestructure is highly disrupted, approximately parallel to the seafloor, and underlain by a 10 - to 20 -m-thick transparent zone adjacent to the slope (Figure 3), signatures suggestive of turbulence. Transparent zones in reflection images indicate lack of finestructure; when surrounded by strong reflections, such zones can be interpreted as mixed, nearly homogeneous layers. Just downslope of the interpreted turbulence is a zone of finestructure splitting approximately $2 \mathrm{~km}$ wide and 50-80 $\mathrm{m}$ high, which likely represents isotherm splitting, a phenomenon that has been observed and attributed to turbulent mixing on continental slopes [Navrotsky et al., 2004].

[13] We note that, in a static ocean, the inclination of reflections measured on seismic sections are a minimum inclination, since the ship tracks intersect the internal wave surfaces at an arbitrary azimuth; true dips can be steeper, but not shallower, than those imaged. (In the pathological case, a seismic section shot along the strike direction of a planar dipping target will produce a flat image.) However, if the internal wave beams imaged here are produced locally at the continental slope, we expect that our profiles, which were acquired perpendicular to the shelf break, capture approximately the true dip of the beams.

[14] Due to the dominant vertical wavelength of seismic data (typically $\sim 30 \mathrm{~m}$ ), the vertical strains associated with internal tidal beams are amenable to seismic imaging only in cases where high-mode wave strains are present. Lowmode internal tides, such as the first mode internal tides thought to propagate over large distances [Ray and Mitchum, 1997], will create only gradual vertical strains that will be invisible to the wavelengths of seismic reflection data. Seismic imaging is thus most applicable to detecting internal tides near local sources of generation or dissipation, such as continental shelf breaks, near-critical continental slopes, and seamounts.

[15] The work presented here adds a key oceanographic process - generation of internal tides - to the list of those amenable to detection and study by seismic oceanography techniques. We suggest that future seismic oceanography studies over seamounts and critically inclined continental slopes, where internal tides are expected, will provide useful information on the presence and distribution of internal tides, and their relationship to ocean mixing.

[16] Acknowledgments. This work was supported by Office of Naval Research grant N00014-04-1-0585 and by NSF's Ocean Drilling Program (grant OCE-0221366) and Physical Oceanography Program (grants OCE0337289, OCE-0452744, and OCE-0648620). We thank the officers and crew of the R/V Maurice Ewing, and S. Pearse, P. Páramo, P. Nandi, H. Brown, and $\mathrm{J}$. Nealon for data acquisition assistance and initial processing. Data were processed using Paradigm's Focus package, Matlab and Generic Mapping Tools. The authors thank D. Lizarralde, L.C. Helfrich, E.B. Wilson, P. Páramo, S. Thorpe, and B. Ruddick for valuable discussions.

\section{References}

Alford, M. H., and Z. X. Zhao (2007), Global patterns of low-mode internal-wave propagation. Part I: Energy and energy flux, J. Phys. Oceanogr. 37, 1829-1848, doi:10.1175/JPO3085.1.

Baines, P. G. (1982), On internal tide generation models, Deep Sea Res., Part A, 29, 307-338, doi:10.1016/0198-0149(82)90098-X.

Biescas, B., V. Sallares, J. Pelegri, F. Machin, R. Carbonell, G. Buffett, J. Danobeitia, and A. Calahorrano (2008), Imaging meddy finestructure using multichannel seismic reflection data, Geophys. Res. Lett., 35, L11609, doi:10.1029/2008GL033971.

Bullock, A. D. (2006), Enhanced finestructure around an intrathermocline lens in the Norwegian Sea, Eos Trans. $A G U, 87(36)$, Ocean Sci. Meet. Suppl., Abstract OS13I-04.

Cacchione, D. A., L. F. Pratson, and A. S. Ogston (2002), The shaping of continental slopes by internal tides, Science, 296, 724-727, doi:10.1126/ science. 1069803 .

Cole, S. T., D. L. Rudnick, B. A. Hodges, and J. P. Martin (2009), Observations of tidal internal wave beams at Kauai Channel, Hawaii, J. Phys. Oceanogr., 39, 421-436, doi:10.1175/2008JPO3937.1.

Dauxois, T., A. Didier, and E. Falcon (2004), Observation of near-critical reflection of internal waves in a stably stratified fluid, Phys. Fluids, 16, 1936-1941, doi:10.1063/1.1711814.

Egbert, G. D., and R. D. Ray (2000), Significant dissipation of tidal energy in the deep ocean inferred from satellite altimeter data, Nature, 405, 775-778, doi:10.1038/35015531.

Eriksen, C. C. (1985), Implications of ocean bottom reflection for internal wave spectra and mixing, J. Phys. Oceanogr., 15, 1145-1156, doi:10.1175/1520-0485(1985)015<1145:IOOBRF>2.0.CO;2.

Garrett, C., and E. Kunze (2007), Internal tide generation in the deep ocean, Annu. Rev. Fluid Mech., 39, 57-87, doi:10.1146/annurev.fluid.39. 050905.110227. 
General Bathymetric Chart of the Oceans (2004), Gridded bathymetry data, Br. Oceanogr. Data Cent., Liverpool, U. K., (Available at http:// www.gebco.net/data_and_products/gridded_bathymetry_data/).

Holbrook, W. S., and I. Fer (2005), Ocean internal wave spectra inferred from seismic reflection transects, Geophys. Res. Lett., 32, L15604, doi:10.1029/2005GL023733.

Holbrook, W. S., P. Páramo, S. Pearse, and R. W. Schmitt (2003), Thermohaline fine structure in an oceanographic front from seismic reflection profiling, Science, 301, 821-824, doi:10.1126/science.1085116.

Ivey, G. N., and R. I. Nokes (1989), Vertical mixing due to the breaking of critical internal waves on sloping boundaries, J. Fluid Mech., 204, 479-500, doi:10.1017/S0022112089001849.

Krahmann, G., P. Brandt, D. Klaeschen, and T. Reston (2008), Mid-depth internal wave energy off the Iberian Peninsula estimated from seismic reflection data, J. Geophys. Res., 113, C12016, doi:10.1029/ 2007JC004678.

Legg, S., and A. J. Adcroft (2003), Internal wave breaking on concave and convex continental slopes, J. Phys. Oceanogr., 33, 2224-2246, doi:10.1175/1520-0485(2003)033<2224:IWBACA>2.0.CO;2.

Lien, R. C., and M. C. Gregg (2001), Observations of turbulence in a tidal beam and across a coastal ridge, J. Geophys. Res., 106, 4575-4591, doi:10.1029/2000JC000351.

Lueck, R. G., and T. D. Mudge (1997), Topographically induced mixing around a shallow seamount, Science, 276, 1831-1833, doi:10.1126/ science.276.5320.1831.

Martin, J. P., and D. L. Rudnick (2007), Inferences and observations of turbulent dissipation and mixing in the upper ocean at the Hawaiian Ridge, J. Phys. Oceanogr., 37, 476-494, doi:10.1175/JPO2992.1.

Moum, J. N., D. R. Caldwell, J. D. Nash, and G. D. Gunderson (2002), Observations of boundary mixing over the continental slope, J. Phys. Oceanogr., 32, 2113-2130, doi:10.1175/1520-0485(2002)032<2113: OOBMOT $>2.0 . \mathrm{CO} ; 2$.

Nakamura, Y., T. Noguchi, T. Tsuji, S. Itoh, H. Niino, and T. Matsuoka (2006), Simultaneous seismic reflection and physical oceanographic observations of oceanic fine structure in the Kuroshio extension front, Geophys. Res. Lett., 33, L23605, doi:10.1029/2006GL027437.

Nandi, P., W. S. Holbrook, S. Pearse, P. Páramo, and R. W. Schmitt (2004), Seismic reflection imaging of water mass boundaries in the Norwegian Sea, Geophys. Res. Lett., 31, L23311, doi:10.1029/2004GL021325.
Nash, J. D., E. Kunze, J. M. Toole, and R. W. Schmitt (2004), Internal tide reflection and turbulent mixing on the continental slope, J. Phys. Oceanogr., 34, 1117-1134, doi:10.1175/1520-0485(2004)034<1117: ITRATM $>2.0 . \mathrm{CO} ; 2$.

Navrotsky, V. V., I. D. Lozovatsky, E. P. Pavlova, and H. J. S. Fernando (2004), Observations of internal waves and thermocline splitting near a shelf break of the Sea of Japan (East Sea), Cont. Shelf Res., 24, 1375-1395, doi:10.1016/j.csr.2004.03.008.

Pingree, R. D., and A. L. New (1989), Downward propagation of internal tidal energy into the Bay of Biscay, Deep Sea Res., Part A, 36, 735-758, doi:10.1016/0198-0149(89)90148-9.

Ray, R. D., and G. T. Mitchum (1997), Surface manifestation of internal tides in the deep ocean: Observations from altimetry and island gauges, Prog. Oceanogr., 40, 135-162, doi:10.1016/S0079-6611(97)00025-6.

Ruddick, B. (1992), Intrusive mixing in a Mediterranean salt lens: Intrusion slopes and dynamical mechanisms, J. Phys. Oceanogr., 22, 1274-1285, doi:10.1175/1520-0485(1992)022<1274:IMIAMS>2.0.CO;2.

Ruddick, B., H. B. Song, C. Z. Dong, and L. Pinheiro (2009), Water column seismic images as maps of temperature gradient, Oceanography, $22,192-205$.

Rudnick, D. L., et al. (2003), From tides to mixing along the Hawaiian Ridge, Science, 301, 355-357, doi:10.1126/science. 1085837.

Thorpe, S. A. (1987), On the reflection of a train of finite amplitude internal gravity waves from a uniform slope, J. Fluid Mech., 178, 279-302, doi:10.1017/S0022112087001228.

Thorpe, S. (2005), The Turbulent Ocean, 437 pp., Cambridge Univ. Press, Cambridge, U. K.

Tsuji, T., T. Noguchi, H. Niino, T. Matsuoka, Y. Nakamura, H. Tokuyama, S. Kuramoto, and N. Bangs (2005), Two-dimensional mapping of fine structures in the Kuroshio Current using seismic reflection data, Geophys. Res. Lett., 32, L14609, doi:10.1029/2005GL023095.

I. Fer, Geophysical Institute, University of Bergen, Allegaten 70, N-5007 Bergen, Norway.

W. S. Holbrook, Department of Geology and Geophysics, University of Wyoming, 1000 E. University Ave., Laramie, WY 82071, USA. (steveh@uwyo.edu)

R. W. Schmitt, Department of Physical Oceanography, Woods Hole Oceanographic Institution, 266 Woods Hole Rd., Woods Hole, MA 02543, USA. 